\title{
ANTONIO CASO, EDUCADOR UNIVERSITARIO
}

\author{
Morelos Torres Aguilar ${ }^{1}$ \\ Universidad de Guanajuato - México \\ Grupo de investigación HISULA \\ morelostorres@gmail.com
}

Recepción: 13/09/2010

Evaluación: 28/02/2011

Aceptación: 22/07/2011

Artículo de Reflexión

\section{RESUMEN}

El artículo es producto de una investigación sobre la trayectoria de Antonio Caso como educador universitario, y se centra en el período de la Revolución Mexicana y la posrevolución. En forma complementaria, se analizan algunas aportaciones del maestro Caso realizadas durante los años 30 del siglo pasado, en particular en el debate sobre la educación socialista y en la formación de intelectuales. El trabajo analiza las principales ideas y acciones de este educador mexicano, relacionadas directamente con las funciones educativas y universitarias.

Palabras clave: Revista Historia de la Educación Latinoamericana, Antonio Caso, docencia, universidad, filosofía, intelectuales.

1 Doctor en historia por la Universidad Nacional Autónoma de México. Obtuvo mención honorífica y la medalla Alfonso Caso de esta institución por sus estudios de doctorado. Es profesor en el Doctorado en Cultura y Arte de la Universidad de Guanajuato, integrante de la Red de Historiadores de la Prensa y el Periodismo en Iberoamérica, del Seminario Permanente Tiempo Espacio, y del grupo de investigación Historia y Prospectiva de la Universidad Latinoamericana. Forma parte del Sistema Nacional de Investigadores en México. 


\title{
ANTONIO CASO, UNIVERSITY EDUCATOR
}

\author{
Morelos Torres Aguilar \\ Universidad Autónoma de Chiapas - México \\ Research group HISULA \\ morelostorres@gmail.com
}

\begin{abstract}
The article is the result of a research about the career of Antonio Caso as university educator, and it focuses on the period of the Mexican Revolution and the post-revolution. As a complementary way, it discusses some Master Caso's contributions that he made during the 30's of last century, particularly in the debate on socialist education and training of intellectuals. The work analyzes the main ideas and actions of the Mexican educator, directly related to educational and university functions.
\end{abstract}

Key words: Journal of Latin American Education History, Antonio Caso, teaching, university, philosophy, intellectuals.

\section{ANTONIO CASO, EDUCADOR UNIVERSITÁRIO}

\author{
Morelos Torres Aguilar \\ Universidad Autónoma de Chiapas - México \\ Grupo de pesquisa HISULA \\ morelostorres@gmail.com
}

\section{RESUMO}

Este artigo é produto de uma pesquisa sobre a trajetória de Antonio Caso como educador universitário, e se centra no período da Revolução Mexicana e na pós-revolução. De forma complementar, se analisam algumas contribuições do professor Caso realizadas durante os anos 30 do século passado, em particular no debate sobre a educação socialista e na formação de intelectuais. $\mathrm{O}$ trabalho analisa as principais ideias e ações deste educador mexicano, relacionadas diretamente com as funções educativas e universitárias. 
Palavras-chave: Revista História da Educação Latino-americana, Antonio Caso, docência, universidade, filosofia, intelectuais.

\section{INTRODUCCIÓN}

Este trabajo examina la trayectoria de Antonio Caso como educador universitario, desde su cátedra en la Universidad Popular Mexicana, y sobre todo en la Universidad Nacional de México. ${ }^{2}$ De las diversas facetas mostradas por este notable intelectual mexicano, una de las más importantes, aunque menos examinadas en tiempos recientes, es su labor como docente. Por ello, el principal objetivo de este trabajo es rescatar su figura como maestro de diversas generaciones, y como formador de importantes intelectuales.

Antonio Caso perteneció a la generación del Centenario ${ }^{3}$, integrada por personalidades como José Vasconcelos, Martín Luis Guzmán, Pedro Henríquez Ureña, Alfonso Reyes, Carlos González Peña, Nemesio García Naranjo, Jenaro Fernández Mac Gregor, Enrique González Martínez, Alfonso Pruneda, Alberto J. Pani y Manuel M. Ponce, entre otros intelectuales que formaron parte del Ateneo de la Juventud o del Ateneo de México, a comienzos de la Revolución Mexicana. De ellos, la figura más conocida en el campo de la educación es sin duda la de José Vasconcelos, de quien se han publicado numerosos trabajos que analizan su gran contribución, sobre todo desde la Secretaría de Educación Pública de México, a comienzos de los años veinte del siglo pasado ${ }^{4}$.

La obra de Caso como educador, en tanto, fue reconocida en su momento por diversos autores durante la primera mitad del siglo XX, mientras que en décadas recientes ha sido revalorada sobre todo su obra filosófica. El hecho de que hayan trascendido más sus ideas que sus vivencias en las aulas universitarias resulta natural: en la mayoría de los casos las obras sobreviven a la persona, y además, por lo general se le otorga una mayor importancia a la cultura escrita que a la cultura oral. Los numerosos profesionales a quienes Caso tuvo como alumnos han ido falleciendo, y con ellos, ha desaparecido también un importante cúmulo de recuerdos y anécdotas que se guardaban sobre este personaje. Lo que ocurre en el aula,

2 Es decir, antes de 1929, año en que la Universidad Nacional obtuvo su autonomía. Aunque, como ya se mencionó, se abordarán también algunos episodios posteriores.

3 Así la llaman, en distintos momentos, Alfonso Reyes y Luis Cardoza y Aragón, entre otros.

4 Entre ellos el de Javier Ocampo, quien explora atinadamente el itinerario del filósofo mexicano. OCAMPO LÓPEZ, Javier. (2005): "José Vasconcelos y la educación mexicana", en Revista Historia de la Educación Latinoamericana, Vol. 7, pp. $137-157$. 
ese momento efímero que constituye la cátedra, sólo queda en la memoria de los concurrentes, pero no es frecuente que sea recogido en documentos tales como diarios, correspondencia y memorias. Una clase es un episodio irrepetible, a veces incluso inenarrable, como lo saben quienes se han dedicado a la enseñanza. Porque según diversos testimonios, de Caso pudo decirse lo mismo que Emilio Uranga escribió acerca de José Gaos: "Quien no lo oyó, lo perdió"5.

La trayectoria de Antonio Caso como educador universitario es un tema que ha sido mencionado sólo en forma esporádica dentro de los escritos relacionados con el personaje. Los recuerdos sobre Caso que han sobrevivido se diluyen, y en ellos sólo aparecen, en forma dispersa, algunas de las características que lo representaban como un profesor admirable en la memoria de sus discípulos. Cuando se analiza su obra como filósofo, por ejemplo, es difícil encontrar una explicación para la notable influencia que llegó a tener sobre los miembros de generaciones posteriores. De alguna manera, la figura del gran maestro se ha desvanecido junto a los alumnos que percibieron sus virtudes.

La investigación pretende caracterizar la forma de enseñanza de Caso, y conocer cuál era su desempeño en el aula, en la conferencia, frente a un público, sea en el ámbito universitario, o en el seno de la sociedad en general, a la que también se dirigía. Asimismo, el propósito que guía este trabajo es conocer la trascendencia que tuvo la obra de Caso como educador en las generaciones que le sucedieron.

De esta manera, el primer problema que se plantea es analizar su actuación en las aulas, con el fin de profundizar en la postura ideológica, metodológica y moral que asumía en sus clases, y que comunicaba no sólo enseñanzas sobre diversos temas, sino determinado modelo de conducta.

El segundo problema consiste en conocer los temas de algunas de sus cátedras notables y sus conferencias universitarias, principalmente en el período de la Revolución Mexicana y en el México posrevolucionario. En éstas, el filósofo desplegó su imaginación, su intuición, su pasión.

El tercer problema que sirve como fundamento a la investigación, reside en comprender la relación que Caso guardó con algunos alumnos notables, pues ésta permitirá saber si el maestro influyó realmente, en

5 URANGA, Emilio. (1969): “José Gaos: personalidad y confesión", en Cuadernos Americanos. México. Año XXVIII. Vol. CLXVI. No. 5. septiembre - octubre. pp. 130 - 156. También citado en la nota de edición de Andrés Lira a GAOS, José. (1983): Historia de nuestra idea del mundo. México. Fondo de Cultura Económica. 
forma decisiva, sobre ellos, sobre sus trayectorias, sus vocaciones y sus destinos. Finalmente, el cuarto problema consiste en interpretar, a la luz de los documentos consultados, la trayectoria de Antonio Caso como educador universitario. A partir de dichos problemas, fueron establecidos los siguientes objetivos:

1. Describir a Antonio Caso como ser humano, señalando las virtudes y los defectos personales que influían en su labor docente, a partir de los testimonios de sus alumnos y sus contemporáneos.

2. Caracterizar la postura ideológica, existencial y moral de Caso, que se apreciaba en sus actividades cotidianas, y que era transmitida a sus alumnos.

3. Describir los principales temas abordados por Caso en su cátedra y sus conferencias, en particular durante la Revolución Mexicana, y destacar algunos ejemplos notables de su labor educativa en el mismo período.

4. Examinar su actuación en las aulas, mediante el análisis de los documentos que describen las características de su práctica docente.

5. Analizar la relación del maestro con algunos alumnos notables, intelectuales que posteriormente fueron conocidos por su obra en diversos campos del conocimiento, señalando los aspectos en que resulta palpable la influencia de Caso en la trayectoria de éstos, y también los factores que propiciaron posteriormente el distanciamiento entre el maestro y sus discípulos.

El objetivo final consiste en interpretar la trascendencia que tuvo Antonio Caso como educador universitario, con base en la investigación planteada.

El método utilizado para cumplir los objetivos antedichos consistió en la revisión hemerográfica de algunos episodios decisivos en la trayectoria docente de Antonio Caso. Para ello fueron consultados algunos diarios editados en la ciudad de México entre 1910 y 1920: El Imparcial, El Demócrata, El Heraldo de México, El Pueblo y Excélsior, entre otros. Del mismo modo, fue revisada su trayectoria al interior del Ateneo de la Juventud y el Ateneo de México, lo cual aportó algunos elementos para atender el primero y el cuarto objetivos.

La investigación se apoyó también en un análisis de algunas de las principales obras del filósofo, sobre todo La existencia como economía, como desinterés y como caridad, que a decir de José Gaos "es todo un sistema filosófico; aunque sólo in nuce, bastará a mostrarlo el llamar la atención sobre el hecho de que los distintos capítulos del "ensayo" abocetan sendas versiones de las partes de la filosofía integrantes de un sistema 
cabal de ésta". La revisión de la obra de Caso resulta importante porque en ella se encuentran presentes las principales líneas de pensamiento, las perspectivas lógicas, y sobre todo morales, que utilizaba primordialmente cuando hablaba frente en el aula o en el auditorio.

Asimismo, la revisión de un amplio conjunto de artículos publicados en revistas especializadas, y en libros sobre el tema, permitió complementar y enriquecer la investigación, gracias a los análisis que los investigadores realizaron y publicaron sobre temas como la obra filosófica de Caso, su eclecticismo, su voluntarismo, su imaginario nacional, su pensamiento histórico, su concepción del ser humano, su propuesta espiritual, su perspectiva moral y su concepto de intuición.

En particular, resultan muy útiles los artículos que analizan las redes filosóficas y profesionales de las que Caso formaba parte, y aquellos en donde se examinan las polémicas que sostuvo el maestro con oponentes formidables como Agustín Aragón y Vicente Lombardo Toledano, quien había sido no sólo su alumno, sino su amigo. Fue también útil conocer los motivos de su distanciamiento con Samuel Ramos, otro gran filósofo mexicano que fue también en su momento uno de sus alumnos predilectos. Del mismo modo, los artículos en donde se aborda el pensamiento estético del ateneísta revelan el interés que tenía en estudiar el fenómeno de las artes, y la lógica de la imaginación y los sentimientos.

Por último, una vez reunidas las ideas surgidas de las fuentes, se compararon entre sí, con el fin de encontrar y articular las líneas cardinales del pensamiento y la práctica educativa del filósofo. Es decir, se realizó una revisión hermenéutica de los textos, que permitió interpretarlos, centrando las categorías de análisis, en forma específica, en el ámbito educativo y en el propósito docente de Caso, que no sólo estaba dirigido a los estudiantes universitarios, sino al público en general que asistía, por ejemplo, a las conferencias que impartió en la Universidad Popular Mexicana.

\section{Antonio Caso en la mirada de sus contemporáneos.}

En 1946, Carlos González Peña publica Gente mía, un libro en donde describe de manera íntima sus recuerdos acerca de los integrantes del Ateneo de la Juventud. Cuando evoca la figura de Caso, del joven filósofo fundador del propio Ateneo, escribe:

${ }^{6}$ GAOS, José. (1952): En torno a la filosofía mexicana. México. Porrúa y Obregón. Tomo I. p. 65. También en FLORESCANO, Enrique (1963): "Antonio Caso y la Historia", en Historia Mexicana. México. Vol. XII. No. 3. Enero - marzo. pp. 358-378. 
¿Quién era Caso? Coincidiendo con los primeros movimientos de integración del nuevo grupo literario [el Ateneo], su nombre babía empezado a sonar y su personalidad a delinearse. Señalábase por una extraña elocuencia persuasiva, por un raro y macizo saber aquel mozo de lacia cabellera endrina peinada hacia atrás, de ojos que fulguraban o reían, con simpatía infinita, bajo el arco de las cejas, de prominentes quijadas que se destacaban y como que acentuaban y rubricaban la morena faz tallada a vigorosos golpes de cincel. Cuando hablaba en público, avasallaba concursos; cuando en privado, ganaba amigos. ¿Orador? La palabra no existía para él en función vacua y exclusiva; era, antes bien, instrumento de buen razonar y formidable vebículo de ideas. Cantaba, musicalmente esplendía, ataviándose con las más ricas galas; pero hacía algo más: convencía y enseñaba. ¡Enseñaba siempre! No era un orador o era algo más que un orador: un filósofo y un maestro. Su ambiente natural no lo constituía la tribuna, sino la cátedra. Su actividad más cara concentrábase en pensar. En pensar, para enseñar y para escribir. Y como, además del prestigio del saber auténtico, atraía por su generosidad intelectual, por su personal simpatía, por aquel don de gentes, alternativamente austero y risueño, cortés y cordial, por su pasión arrolladora, desbordada que fluia en entusiasmos, naturalmente bubo de convertirse, dentro de su generación, en un congregador de espíritus, atributo supremo de la maestría. Su influencia en la generación contemporánea fue, por lo mismo, inmensa. Influencia en el sentido de estímulo, no de sujeción; fecunda por libérrima. Todo, dentro del Ateneo, coexistía y se vivificaba en la pasión de saber y trabajar. En el estudio de Caso, donde presidía el busto marmóreo de un Goethe que miraba sin ver, la inteligencia recibió impulsos insospechados y cobró alas?.

Luego, en forma contrastante, González Peña recuerda también al Caso ya maduro, al de los últimos días:

Dispersa la falange, su abanderado, el joven filósofo, continúa la marcha. Sigue de frente con la cabeza erguida. Argento blanquea, lentamente, la endrina melena de ayer. Hay polvo y pedruscos; pero, aquí y allá, flores en los ribazos, y alegre algarabía de pájaros celados por las frondas. El caminante se fortalece. Antes que vaciarse, milagrosamente se llenan las alforjas... un destino puro, de intima consecuencia con el propio pensar, de generoso desinterés; un alto y jamás saciado anbelo de conocer y enseñar; una veintena de libros fuertes y bellamente escritos; un nombre sin tacha.

${ }^{7}$ GONZÁLEZ PEÑA, Carlos. (1946): "Antonio Caso y la generación del Ateneo", en CASO, Antonio; REYES, Alfonso, et al. (2000): Conferencias del Ateneo de la Juventud. Seguido de Anejo documental. México. Universidad Nacional Autónoma de México - Coordinación de Humanidades. p. 491

8 Ibídem p. 492 
La descripción de González Peña aporta interesantes elementos para conocer la imagen que tenían de Caso sus coetáneos, su propia generación. Otra persona que conoció profundamente al docente -de hecho, desde su niñez- fue Isidro Fabela, también ateneísta, diplomático, político, intelectual de altura. Escribe Fabela:

El sentimiento más vivo de Antonio Caso fue la bondad. Desde niño fue siempre bueno, porque así nació, porque no concebía hacer daño a nadie deliberadamente; porque no entendió nunca cómo la maldad puede existir en el corazón bumano y ejercitarse en los demás... no supo lo que es el rencor, desdeñó el odio y jamás pensó en represalias o venganzas... el dolor ajeno lo conmovía hasta el llanto, pero el propio lo sobrellevaba con entereza... el dolor fue su compañero y su maestro: lo amó porque en él aprendió a engrandecer y vigorizar su espiritu... A Antonio Caso lo admiré desde que siendo preparatorianos penetré en su espiritu donde tenía cabida una de las inteligencias más preclaras y profundas que be conocido, y una de las bondades más puras y más sinceras que el ser bumano pueda tener. Desde sus años mozos tenía entre sus compañeros el procerato del talento y la sabiduría. Era poeta, pensador y músico. Las primeras manifestaciones de su alma de artista las expresó en versos románticos, entusiastas, líricos, que recitaba admirablemente con lágrimas en los ojos, porque era un sentimental desbordante. $Y$ al propio tiempo que poeta, era músico. Tocaba, no exagero, admirablemente; su ejecución era limpia y su interpretación, de una emotividad rara y seductora. Tocando Chopin, mojaba con lágrimas las teclas del piano... Caso hizo de su vida una obra maestra de libertad, sin tener otra ambición que la de saber más cada día, sin más deseo que el de su soledad y su ensimismamiento; sin afán de honores, ni de glorias, ni de dinero, y sin más ilusión que la de gozar una plena independencia. Porque fue, antes que todo, un hombre libre que ganó su emancipación a fuerza de rebeldías, de dignidady de pobrezas. Si se me preguntara cuál fue la virtud suprema de Caso, yo diría: su autonomía espiritual, porque Antonio Caso fue un hombre integramente independiente y enseñó a los demás a pensar y vivir como seres libres. Buscando la verdad y enseñándola con una gran cordialidad docta y serena, y amando todo lo que es hermoso y rítmico, es como pasó su existencia toda este pensador artista... En Caso todo es pasión: estudio, la cátedra, el amor y el dolor?.

Vasconcelos, por su parte, ve a Caso como un "constructor de rumbos mentales y un libertador de los espíritus [que] gusta de enseñar y fortalecer las convicciones y de acoger con calor todos los credos, tan sólo por el placer de destruirlos con crítica luminosa y felicísima. A su contacto, la

9 FABELA, Isidro. (1959): “Antonio Caso. El hombre", en Antología del pensamiento universal, de Isidro Fabela. Editorial Costa - Amic. Tomo I. pp. $128-132$ 
bruma de las almas se disipa y disuelve en claridad, como el cielo después de los relámpagos. Su doctrina es la del jardinero que da a sus flores humus fecundo, agua y luz, y goza en seguida mirándolas lucir profusa variedad"10.

El educador oaxaqueño lo reconoce asimismo como fundador del Ateneo: "Nuestra agrupación la inició Caso con las conferencias y discusiones de temas filosóficos en el salón del Generalito, de la Preparatoria... La batalla filosófica contra el positivismo. El abanderado fue siempre Caso y nuestro apoyo Boutroux. El libro de éste sobre la contingencia de las leyes naturales, hábilmente comentado, aprovechado por Caso, destruyó en un ciclo de conferencias, toda la labor positivista de los anteriores treinta años... de aquí la doble dirección del movimiento ideológico del Ateneo. Racionalista, idealista con Caso; antiintelectualista, voluntarista y espiritualizante en mi ánimo". ${ }^{11}$

Del mismo modo, recuerda la generosidad de Caso:

Todos mis compañeros escribian a base de citas y entrecomillas. Los libros del propio Caso dan fe de esta tendencia erudita... Me hacía falta discutir, hablar las ideas antes de escribirlas. Con Caso me puse a hablarlas, me ayudó con su instinto de sabio y su visión lúcida... Cuando llegué a definir: "Concepto dinámico del derecho", sentí pasar por la frente un relámpago. Antes que a nadie, lei mis cuartillas a Caso... 'Es curioso -observó-, ha escrito usted bastantes páginas sin hacer cita y sin perder de vista su tema... Es raro que nosotros no podamos escribir así... En fin, es original su trabajo y lo felicito." Y su enhorabuena fue sincera porque, consciente Caso de su propio valer, no conocía la envidia y es por naturaleza generoso ${ }^{12}$.

Sin embargo, Vasconcelos también reprochará a Caso "su carácter apático y a ratos insociable, [que] no hubiera mantenido alianzas sin la colaboración de Henríquez Ureña". ${ }^{13}$ Por su parte, el propio escritor dominicano recordará:

En 1909, antes de que cayera el gobierno de Díaz, Antonio Caso fue llamado a una cátedra de la que hoy es Universidad Nacional y su entrada allí significó el principio del fin. Cuando Madero llegó al poder, en 1911, los principales representantes del antiguo pensamiento oficial-que eran en su mayoría personajes políticos del antiguo régimen- se retiraron de la Universidad, y su influencia

${ }^{10}$ VASCONCELOS, José. (1916): "El movimiento intelectual contemporáneo de México", en CASO, Antonio; REYES, Alfonso, et al. (2000): Óp., cit, p. 127

${ }^{11}$ VASCONCELOS, José. (1935): Ulises Criollo. México. Ediciones Botas. p. 266

${ }^{12}$ Ibídem., pp. 268 - 269.

${ }^{13}$ Ibídem., p. 311. 
se desvaneció... Nuestra única conquista fundamental, en la vida universitaria de entonces, fue el estímulo que dio Antonio Caso a la libertad filosófica ${ }^{14}$.

Alfonso Reyes también hará su propia descripción acerca de la importancia que representa la obra de Caso para la formación de una nueva cultura:

La filosofía positivista mexicana... habría de desvanecerse bajo la palabra elocuente de Antonio Caso, quien difundiría por las aulas las nuevas verdades. No hay una teoría, una afirmación o una duda que él no baya becho suyas siquiera un instante, para penetrarlas con aquel intimo conocimiento que es el amor intelectual. La historia de la filosofía, él ha querido y ha sabido vivirla. Con tal experiencia de las ideas, y el vigor lógico que las organiza, su cátedra sería, más tarde, el orgullo de nuestro mundo universitario. Su elocuencia, su eficacia mental, su naturaleza irresistible, lo convertirían en el director público de la juventud ${ }^{15}$.

Reyes también recuerda que Caso presentó en la Escuela de Altos Estudios, con éxito ruidoso y lleno de augurios, su curso libre y gratuito sobre filosofía: "A Antonio Caso, que ya había iniciado la obra desde su curso de Sociología en la Escuela de Derecho, corresponde la honra de haber conducido otra vez a la Filosofía hasta la cátedra. ${ }^{16}$

En cambio, la postura de Henríquez Ureña, otro de los ateneístas fundamentales, será mucho más crítica hacia la figura de Caso. Si bien lo reconoce como un amante de las cuestiones filosóficas, "poseedor del abundante don de la palabra", también le reputa su afán de precisión conceptual, que "vuelve inelegante, imperativa, la frase". Además, considera que a veces "el flujo verbal [de Caso] desvirtúa las ideas o las engendra falsas", señalando que gran parte de los errores que Caso comete en las conferencias proviene de una "censurable confianza en el poder verbal". Sin embargo, a fin de cuentas reconoce el "conocimiento seguro de la evolución del pensamiento europeo" que tiene Caso: conoce a los grandes maestros, y afronta los problemas con criterio independiente ${ }^{17}$.

Martín Luis Guzmán también tiene algo que decir sobre las dotes de Caso como maestro. Primero, reconoce la capacidad del Ateneo para

14 HENRÍQUEZ UREÑA, Pedro. (1925): "La Revolución y la cultura en México”, en CASO, Antonio; REYES, Alfonso, Óp., cit, p. 147 - 148.

15 REYES, Alfonso. (1941): "Pasado inmediato", en CASO, Antonio; REYES, Alfonso, Óp., cit, pp. 198-199.

16 REYES, Alfonso. Óp., cit, p. 205.

${ }^{17}$ HENRÍQUEZ UREÑA, Pedro. (1909): "El positivismo independiente”, en CASO, Antonio; REYES, Alfonso, Óp., cit, p. 324. 
"lograr una fusión inesperada: de una parte, atrajeron hacia su órbita a los representantes más eminentes de generaciones anteriores"; luego, señala que los ateneístas "llevaron su influencia, gracias al brillante magisterio de Antonio Caso, y, más enérgicamente aún, por la persuasión y el trato directo de Pedro Henríquez Ureña, a generaciones más jóvenes" ${ }^{18}$.

Julio Jiménez Rueda, en tanto, destaca sobre las capacidades de Caso en el aula, "la cálida elocuencia que brinda en sus cátedras y conferencias", y la "profundidad no exenta de gracia ni de suave ironía, de alegre mariposeo que da a sus lecciones, por el amor que profesa a sus discípulos... es claro en la exposición, convincente en el razonamiento, colorido en la imagen, galano en el ademán". ${ }^{19}$ Cosío Villegas, por su parte, concede a Caso una importancia aún mayor, cuando declara que durante el álgido período revolucionario, "...la filosofía era Antonio Caso. De hecho, era el único profesor en la Universidad [Nacional] entera, es decir, el ser solitario cuya vida toda estaba fincada en la enseñanza"20.

Sin embargo, pese a su pasión en la cátedra, Caso preparaba concienzudamente sus clases, según se colige de una conversación que tuvo con su discípulo Eduardo García Máynez, quien alguna vez le preguntó quién era el mejor alumno de la clase. En aquella ocasión, el maestro respondió: "Eduardo, puede estar usted seguro de que el alumno más aprovechado de mi clase es Don Antonio Caso".

Tenemos algunas otras pinceladas que describen al personaje. En 1923, tras renunciar a la rectoría de la Universidad Nacional por profundas diferencias con el secretario de Educación Pública, José Vasconcelos, Caso "abre su hogar al periodista Oscar Leblanc, a quien acompaña un fotógrafo que muéstranos al exrector asido a sus pequeñas hijas y a sus libros". Lablanc, a su vez, "lo retrata asido a sus ideales". El entrevistado considera indecorosa la aceptación de Ezequiel A. Chávez de sucederlo al frente de la Universidad y frisa en la amargura: "Yo no aceptaré por ahora ningún cargo público... estoy contento sin él y viviré dedicado al magisterio..."21

Más recuerdos de los ateneístas. Alfonso Pruneda era muy afecto a Antonio Caso. La esposa del funcionario y médico, Dolores, llamaba a Caso cariñosamente bergsoncito, debido a la admiración que Caso sentía por el

18 GUZMÁN, Martín Luis. (1971): "Alfonso Reyes y las letras mexicanas”, en CASO, Antonio; REYES, Alfonso, Óp., cit, p. 487.

19 JIMÉNEZ RUEDA, Julio. (1922): "Prólogo", en CASO, Antonio. Ensayos críticos y polémicos, México (s. e.). p. 10.

${ }^{20}$ COSÍO VILlEGAS, Daniel. (1986): Memorias. México, Joaquín Mortiz / SEP (Lecturas Mexicanas, Segunda Serie, 55). p. 49.

${ }^{21}$ CURIEL, Fernando. (1999): La Revuelta. Interpretación del Ateneo de la Juventud (1906 - 1929). México, UNAM. p. 398. 
filósofo Bergson ${ }^{22}$. Jiménez Rueda describe así a Caso: "Sus costumbres son sencillas y modestas, su tiempo está consagrado al estudio, a la cátedra, a los discípulos y a la familia. Su vida es de austeridad ejemplar y de rectitud inflexible"23.

En suma, por sus diversas virtudes, Caso representaba el modelo que muchos profesores perseguían en el gremio intelectual de la época. Vivía el filósofo en "la burguesa colonia Santa María la Ribera", en una calle propicia "para la meditación y el estudio", y tenía en 1917 un ideal y dos fines: el primero, prosaico, consistía en "tener cubierto el pan cotidiano"; los segundos eran "escuchar música y estudiar metafísica"24.

\section{La postura ideológica, existencial y moral de Caso. Su idea educativa}

En Antonio Caso podemos encontrar distintas facetas de una visión del mundo. En cuanto a su postura frente al fenómeno del poder, Antonio Caso era sin duda uno de los intelectuales menos interesados en la política, si nos circunscribimos al ámbito del Ateneo. En un principio simpatizaba con el régimen de Díaz, sentimiento en que influía la profunda admiración y el respeto que le profesaba a Justo Sierra, ministro de Instrucción Pública del gobierno porfirista. Más adelante, mientras que varios de los ateneístas engrosaron las filas de la Revolución, militantes bajo diversas banderas, en particular tras el acto usurpador de Victoriano Huerta, Caso permaneció en la ciudad de México, independiente, neutral, si bien mantuvo siempre una perspectiva crítica hacia el régimen huertista.

Cuando en 1913 Huerta dispuso, como estrategia preventiva y disciplinaria, la militarización de la educación superior, que comenzó con la Preparatoria, el único profesor que protestó públicamente ante la medida fue precisamente Caso, al declarar que el país necesitaba "escuelas en los cuarteles y no soldados en las escuelas" 25 . Su posición contrastó con la respuesta, entre resignada y complaciente, asumida por la comunidad académica respecto a un hecho tan grave. Un año después, cuando por orden gubernamental fue cerrada la Academia de Bellas Artes, el único que protestó enérgicamente ante el hecho fue, precisamente, $\mathrm{Caso}^{26}$.

22 PRUNEDA BATRES, Dolores. (2002): Entrevista realizada por Morelos Torres Aguilar. México. 14 de mayo. p. 5.

${ }^{23}$ JIMÉNEZ RUEDA, Julio. (1922): “Prólogo”, en CASO, Antonio. Ensayos críticos y polémicos. México. (s. e.) p. 10.

${ }^{24}$ El Demócrata. (1917): jueves 31 de mayo. Portada.

${ }^{25}$ GARCIADIEGO DANTAN, Javier. (1996): "De Justo Sierra a Vasconcelos. La Universidad Nacional durante la Revolución Mexicana”, en Historia Mexicana. Vol. XLVI. No. 4. p. 796.

${ }^{26}$ LOYO, Engracia. (1999): Gobiernos revolucionarios y educación popular en México, 1911 - 1928. México, El Colegio de México, 1999. p. 279. 
En relación con su postura ideológica referente a la educación universitaria, Caso sostuvo una áspera polémica contra Agustín Aragón, en cuatro artículos aparecidos entre el 19 de marzo y el 16 de abril de 1911 en Revista de Revistas. En su vigorosa defensa de la Universidad Nacional, Caso estaba convencido de que ésta debía cerrar sus puertas a todo dogmatismo. Porque eran dos los dogmatismos que veía cernirse sobre la institución naciente, tales que podrían apagar en ella la llama de la libertad: de un lado, un dogmatismo laico, el positivismo; del otro, el dogmatismo religioso representado por el catolicismo. Ante ellos, Caso define el espíritu de la Universidad Nacional de México en estos términos:

Es menester proclamar muy alto lo que ba dicho el educador a quien se ha combatido con encarnizamiento [se refiere aqui a Justo Sierra]; es fundamentalmente preciso abrir de par en par las puertas de la Escuela a todas las escuelas y a los sistemas todos, enseñados rigurosamente conforme a criterios científicos. Sólo así se cumplirá con el deber de educadores y de contemporáneos; sólo así, sin definir dogmas, sin cohibir espiritus, sin imponer tiranías. Queden para las capillas desprestigiadas las religiones intolerantes, los escrúpulos sombríos y los anatemas. La Escuela ha de ir con la razón, con la ciencia, con la historia, con la humanidad, con las realidades eternas y eternamente evolutivas, que han negado ya todas las escolásticas y desahuciado para siempre a todos los idolos... a Dios gracias, ni catolicismo ni positivismo serán confesados por nuestra educación nacional. La Universidad seguirá por su rumbo de independencia $y$ de libertad inalienables... El mismo Augusto Comte continuaría enseñándose en las cátedras de la Universidad, pero ya no como el único y exclusivo sistema filosófico, sino como uno de tantos sistemas elaborados por el ingenio bumano ${ }^{27}$.

En concordancia con esta línea de pensamiento, Caso defenderá más tarde la libertad de cátedra en la Universidad Nacional, cuando ésta se vea amenazada por Lombardo Toledano y su intento de instaurar el materialismo histórico como guía de pensamiento de la institución. En esta ocasión, Caso dejará claramente establecidos los que considera tres principios fundamentales para la supervivencia de la Universidad: la libertad de cátedra, la autonomía y el subsidio económico que debe otorgarle el gobierno. Por eso escribe:

Libertad es pensamiento. Pensamiento es libertad. En la esencia del pensar está la autonomía... La "exacta concepción del Universo", que algunos propugnan, es desde luego imposible; porque la exactitud no corresponde a todas las ramas del saber, sino sólo a las ciencias

${ }^{27}$ HERNÁNDEZ LUNA, Juan. (1967): "Sobre la fundación de la Universidad Nacional. Antonio Caso vs Agustín Aragón”, en Historia Mexicana. México. El Colegio de México. Vol. XVI. No. 3. p. 379. 
matemáticas; pero si se lograre en los sectores del conocimiento en que ella es posible, sólo lo sería merced a la libertad de la investigación y la autonomía del criterio filosófico ${ }^{28}$.

En cuanto a su visión sobre la civilización, Caso sostiene que no existe progreso físico, filosófico, estético ni moral. En contraposición, "sólo el progreso intelectual, científico y práctico ha sido hecho. El progreso omnilateral no ha existido ni existe. Por eso la creencia en el mejoramiento de la humanidad es una superstición genuinamente moderna"29.

De otra parte, la visión ontológica de Caso, su idea del ser humano entendido como individuo resultaba tan clara, que seguramente era transmitida de diversas formas en la cátedra del maestro. Ya desde sus años formativos como grupo, la joven generación del Ateneo había recibido la importante influencia de José Enrique Rodó, quien en sus obras proponía como virtudes fundamentales del ser humano el idealismo, el desinterés, la nobleza, la comunión y el compartimiento de la belleza. En concordancia con esta línea de pensamiento, para Caso el hombre "es un ser que se sacrifica, un extraordinario ser que siente más placer en la actividad que le causa el mayor dolor, pero que beneficia al semejante" 30 .

Para este hombre integral, este ser humano ideal que no teme al sacrificio y que busca el beneficio de los otros,

El bien no es un imperativo, una ley de la razón, como lo pensó Kant, sino un entusiasmo. No manda, nunca manda, inspira. No impone, no viene de fuera, brota de la conciencia intima, del sentimiento que afianza sus raíces en las profundidades de la existencia espiritual. Es como la música que subyuga y encanta, fácil, espontáneo, intimo, lo más intimo del alma... La caridad es la experiencia fundamental religiosa y moral. Consiste en salir fuera de uno mismo, en darse a los demás, en ofrecerse, en brindarse y prodigarse sin miedo de sufrir agotamiento... la caridad es un becho como la lucha. No se demuestra, se practica, se hace, como la vida. Es otra vida. No tendréis nunca la intuición del orden que se opone a la vida biológica, no entenderéis la existencia en su profunda riqueza, la mutilaréis sin remedio si no sois caritativos... El que no se sacrifica no entiende el mundo total ni es posible explicárselo, como no es posible explicar lo que sea el sonido a un sordo o a un ciego de nacimiento la luz... Hay que tener todos los datos, que ser hombre

${ }^{28}$ CASO, Antonio. (1985): "La cultura universitaria y el materialismo histórico", en CASO, Antonio. Obras completas. México. Universidad Nacional Autónoma de México. Tomo X. pp. 151.

${ }^{29}$ FLORESCANO, Enrique. Óp., cit, p. 367.

${ }^{30}$ CASO, Antonio. (1922): Ensayos críticos y polémicos (con una carta de Êmile Boutroux y un prólogo de Julio Jiménez Rueda). México. (S. E.) p. 25. 
en su integridad; ni ángel ni bestia; para abarcar la existencia como economía y como caridad, como interés y como sacrificio ${ }^{31}$.

Aquí están las claves de la postura moral de Caso: la búsqueda de un ser humano capaz del sacrificio, capaz del desinterés. Un ser generoso que se brinda, que se entrega a los demás, que trasciende su vida biológica, que amplía las fronteras de su existencia por medio de la virtud y el amor:

La caridad es acción. Ve y comete actos de caridad. Entonces, además de sabio, serás santo. La filosofía es imposible sin la caridad; pero la caridad es perfectamente posible sin la filosofía, porque la primera es una idea, un pensamiento, y la segunda una experiencia, una acción. Tu siglo es egoísta y perverso. Ama sin embargo a los hombres de tu siglo que parecen no saber ya amar, que sólo obran por hambre y por codicia. El que hace un acto bueno sabe que existe lo sobrenatural. El que no lo hace no lo sabrá nunca. Todas las filosofías de los hombres de ciencia no valen nada ante la acción desinteresada de un hombre de bien ${ }^{32}$.

Lo que Caso parece buscar, a fin de cuentas, es precisamente el hombre de bien. En esto coinciden diversos autores. Gómez Quiñones señala:

Desde el comienzo de sus estudios, ya en moral o en la historia de la filosofía, Caso tomó inspiraciones eclécticas zigzagueantes, pero también sendas filosóficas claras, idealistas y moralistas, y se apegó a ellas. Destacó el sentimiento ilustrado unido a la acción. En suma, la filosofía idealista de Caso es un Ilamado a la realización personal moral 33 .

Sanginés coincide. Encuentra a un Caso inspirado en Jesucristo y en algunos arquetipos cristianos, que "formula una propuesta que contrapone el ideal cristiano de la caridad a la existencia como economía, egoísmo y lucha por la vida; para llegar a través del sacrificio y la entrega a la obra, a la luz de aquello que 'llama por dentro', para cumplir la misión divina de la redención plena por el amor. Sugiere la salvación personal" 34 . Del mismo modo, Cueva Perus propone: "El valor de Caso estriba en haber buscado

${ }^{31}$ CASO, Antonio. (1916): La existencia como economía y como caridad. Ensayo sobre la esencia del cristianismo. México. Librería de Porrúa Hermanos. pp. 26 - 31

${ }^{32}$ Ibídem., p. 41.

33 GÓMEZ QUIÑONES, Juan. (2007): "Antonio Caso, las ironías de un modernista subversivo", en Relaciones. Estudios de Historia y Sociedad. Zamora. El Colegio de Michoacán. Vol. XXVIII. No. 109. Invierno. p. 191.

${ }^{34}$ SANGINÉS GARCÍA, Esther. (2009): "La transmutación por el espíritu. Ensayo sobre la economía, el amor y el sacrificio en Antonio Caso y José Vasconcelos", en Devenires. Revista de filosofía y filosofía de la cultura. Morelia. Universidad Michoacana de San Nicolás de Hidalgo. Año X. No. 19. Enero de 2009. p. 17. 
ese objeto innombrable, el de la persona humana, en haber sugerido una alternativa cristiana y en haber querido darle vida" 35 .

Respecto a la idea educativa de Antonio Caso como profesor universitario, éste, a juicio de Estrella, proponía una educación que fomentara la libre iniciativa del espíritu del educando, y una pedagogía basada en el respeto por la individualidad del alumno, evitando reducir a éste a un cuerpo impersonal. Aunque Caso no proponía en sus escritos ninguna metodología de enseñanza específica, abogaba por un tipo de enseñanza en la que el filósofo se habría de erigir como el pedagogo por antonomasia, y cuyos métodos responderían antes a la persuasión que a la demostración ${ }^{36}$.

Para Caso el maestro es "sólo un estudiante que ha logrado, por su edad y su saber, alguna ventaja, que le prestan sus años, sobre sus discípulos... el 'fin final' de la cátedra, de la discusión académica, es la consecución de la verdad"37.

\section{Los principales temas abordados por Caso en su cátedra y sus conferencias, en particular durante la Revolución Mexicana. Ejemplos de la labor educativa de Caso en el período.}

Afortunadamente, una de las primeras experiencias de Caso como educador fue recogida en forma completa. La conferencia "La significación y la influencia de Nietzsche en el pensamiento moderno" formó parte del primer ciclo organizado por el Ateneo de la Juventud el 12 de junio de $1907^{38}$. Posteriormente el joven filósofo presentó en el segundo ciclo, el 18 de marzo de 1908, la conferencia "Max Stirner y el individualismo exclusivo"39. Más adelante, vemos a Caso en la Escuela Nacional Preparatoria, concentrado en la campaña antipositivista que emprendió con sus siete conferencias sobre la Historia del Positivismo, sustentadas en los meses de junio, julio y agosto de 1909 ante numerosa concurrencia ${ }^{40}$.

35 CUEVA PERUS, Marcos. (2009): "Antonio Caso, el personalismo y nuestra América”, en Latinoamérica. Revista de Estudios Latinoamericanos. México. Universidad Nacional Autónoma de México. No. 48. Enero - junio. p. 109.

36 ESTRELLA GONZÁLEZ, Alejandro. (2010) "Antonio Caso y las redes filosóficas mexicanas: sociología de la creatividad intelectual", en Revista Mexicana de Sociología 72, No. 2, (abril - junio). México. Universidad Nacional Autónoma de México - Instituto de Investigaciones Sociales. p. 329.

${ }^{37}$ CASO, Antonio. (1985): "La cultura universitaria y el materialismo histórico", en CASO, Antonio, Obras completas. México, Universidad Nacional Autónoma de México. Tomo X. pp. 153.

${ }^{38}$ CASO, Antonio; REYES, Alfonso, et al. Óp., cit, p. 13.

${ }^{39}$ Ibídem., p. 14.

${ }^{40}$ HERNÁNDEZ LUNA, Juan. (1967): "Sobre la fundación de la Universidad Nacional. Antonio Caso vs Agustín Aragón”, en Historia Mexicana. México. El Colegio de México. Vol. XVI. No. 3. pp. 375. 
Posteriormente, dentro del nuevo ciclo de conferencias organizado por el Ateneo con motivo de la conmemoración de la independencia, presentó el 8 de agosto de 1910 la conferencia "La filosofía moral de don Eugenio M. de Hostos", donde asumía para sí una frase del educador puertorriqueño: "la base de la educación deber ser el cultivo de la inteligencia" en 1910, en la Escuela Nacional de Jurisprudencia Caso ofrece un primer acercamiento al materialismo dialéctico, en su curso de sociología; de hecho, en su cátedra comenzaron a formarse los primeros partidarios del marxismo.

Más tarde, en 1913, impartió en la Escuela de Altos Estudios los primeros cursos formales de filosofía en el nivel superior de México en el siglo xx. De ahí en adelante, Caso impartiría diversas cátedras de filosofía en instituciones como la Escuela Nacional preparatoria y la propia Facultad de Filosofía y Letras de la Universidad Nacional de México ${ }^{42}$. En abril de 1913, en la Escuela Nacional de Altos Estudios, Caso imparte su curso de Estética, precedida de nociones de Filosofía General"'43. Entre el 22 de noviembre de 1913 y el 10 de enero de 1914, en el Casino de Santa María, imparte el curso La filosofía de la intuición ${ }^{44}$. A fines de marzo de 1914 Caso, quien era al mismo tiempo director de la Escuela de Altos Estudios y presidente del Ateneo de México, dio en la Universidad Popular Mexicana una conferencia sobre Sócrates ${ }^{45}$. Ese mismo mes el filósofo, que dirigía la Escuela Nacional de Altos Estudios, trabajaba también en la creación de la carrera de Licenciado en Letras, que se habría de estudiar en tres años, y que daba derecho a ser "profesor en las escuelas universitarias" ${ }^{4}$.

En 1915, Caso inauguró el nuevo local de la Universidad Popular Mexicana con la conferencia "El concepto de la Filosofía, especialmente

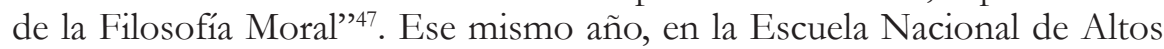
Estudios, daba clase de Estética precedida de nociones de filosofía ${ }^{48}$, y a partir del 25 de noviembre impartió en la Universidad Popular Mexicana, una larga serie de conferencias que habría de ser muy recordada: "La psicología del cristianismo" 49 .

${ }^{41}$ CASO, Antonio; REYES, Alfonso, et al. Óp., cit, p. 33.

${ }^{42}$ SILVA MARTÍNEZ, Guillermo Jorge. (2006): "Antonio Caso (1883-1946)", en MAGALLÓN ANAYA, Mario. (Coord.). Personajes latinoamericanos del siglo XX. México. Universidad Nacional Autónoma de México - Centro Coordinador y Difusor de Estudios Latinoamericanos. p. 69.

${ }^{43}$ El Imparcial, viernes 4 de abril de 1913, p. 7.

${ }^{44}$ CURIEL, Fernando. (1999): Óp., cit, p. 330.

${ }^{45}$ El Imparcial, domingo 29 de marzo de 1914, p. 9.

${ }^{46}$ El Imparcial, sábado 7 de marzo de 1914, p. 6.

47 CASO, Antonio. (1915): "Concepto de la Filosofía, especialmente de la Filosofía Moral", en Boletín de la Universidad Popular Mexicana. Número 1. Mayo. p. 2.

${ }^{48}$ El Norte. Diario de mediodía, lunes 24 de mayo de 1915, p. 3.

${ }^{49}$ El Pueblo, lunes 22 de noviembre de 1915, p. 3. La interpretación de Caso sobre la esencia del Cristianismo sería desarrollada después en La existencia como economía y como caridad. Boletín de la Universidad Popular Mexicana. (1916): Tomo II. número 2. Junio. pp. 49 - 51. 
En 1916, la Universidad Nacional organizó una serie de conferencias sobre temas científicos en el anfiteatro de la Escuela Nacional Preparatoria, a cargo de dos intelectuales muy conocidos y respetados, ambos profesores de la Universidad Popular, Enrique O. Aragón y Antonio Caso, quienes sostuvieron, semana a semana, una especie de diálogo pedagógico. Las conferencias fueron bien recibidas por el público ${ }^{50}$. Ese mismo año, la Generación de 1915, un grupo de jóvenes y entusiastas intelectuales que se reunían con Antonio Caso, fundó la Sociedad de Conferencias y Conciertos con la finalidad de "propagar la cultura entre los estudiantes de la Universidad Nacional de México”. Pronto organizaron un ciclo de conferencias en el Salón de Actos del Museo Nacional de Arqueología ${ }^{51}$. En noviembre, Antonio Caso dio una conferencia en la sala de conciertos de la Casa Alemana de Música con el título "El arte como desinterés" 52.

A principios de mayo de 1917, Caso ofreció una conferencia con el tema "La Filosofía Contemporánea Francesa" en la Academia Metropolitana ${ }^{53}$. En agosto del mismo año dio una conferencia sobre la vida de Beethoven, dentro de un programa musical organizado por Bellas Artes ${ }^{54}$. Aunque éstos son sólo algunos ejemplos de la actividad docente del filósofo, permiten tener una idea de los temas que trataba en la cátedra y en las conferencias.

Dentro de su trayectoria oficial como docente, Caso fue profesor de Lógica y de Historia de la Filosofía en la Escuela Nacional Preparatoria; de Sociología en la Facultad de Derecho y Ciencias Sociales; y finalmente, de Filosofía de la Historia y de Historia de la Filosofía, de Epistemología, de Estética y de Ética en la Facultad de Filosofía y Letras de la Universidad Nacional.

\section{La actuación de Caso en las aulas}

En abril de 1906, a la edad de veintitrés años y siendo estudiante de la Escuela de Leyes, el joven Caso tomó parte en las oposiciones a una cátedra de Historia Universal en la Escuela Nacional Preparatoria. Se dice que no triunfó en la prueba porque la clase estaba destinada de antemano a un

${ }^{50}$ Caso abordó temas como: Noción general de organismo debida a Claude Bernard; Los fenómenos sociales que se han equiparado por los organicistas a las funciones cardinales de la vida; Valor del organicismo como teoría sociológica; La Ley de los Tres Estados (teológico, metafísico y positivo), base fundamental de la sociología, según Augusto Comte; La tesis del materialismo histórico, según Karl Marx; La tesis intelectualista de Comte y la antítesis materialista de Marx se pueden conciliar por virtud de la síntesis que revela el papel social de la invención; ¿Cuál es el elemento social, el grupo humano o el individuo?; La concepción sociológica del mundo. El Pueblo, sábado 26 de agosto de 1916, p. 2.

${ }^{51}$ El Pueblo, domingo 10 de septiembre de 1916, p. 4.

${ }^{52}$ El Pueblo, miércoles 22 de noviembre de 1916, p. 6.

${ }^{53}$ El Pueblo, martes 8 de mayo de 1917, p. 2.

${ }^{54}$ El Demócrata, lunes 20 de agosto, Portada. 
candidato oficial, pero la prensa hizo grandes elogios del opositor. Gaos cita una reseña periodística de la época en la que se lee:

Entre la multitud agolpada a las puertas del salón, se abrió paso un joven como de cera, quien nerviosamente se apoderó de la tribuna, sacudió la melena y rompió a hablar como un inspirado... fue una brillantísima disertación de pensador bondo, dentro de las modernas corrientes del pensamiento... dentro del más elevado criterio filosófico. Tomó las figuras culminantes de la Revolución Francesa, y les extrajo su psicología, y les arrancó sus ideas, y les desarticuló sus tendencias y les pulverizó sus sofismas. Tomó la época, y la presentó sacudida, agrietada, convulsiva... Caso posee temperamento de orador. El gesto, el ademán, la palabra, todo es en Caso grande y admirable. La hermosa cabeza que lleva sobre los hombros, adornada de una crin luenga y bruna, cierra el movimiento de la cláusula, espontánea, vibrante y radiosa. Produjo el frenesí en el aplauso ${ }^{55}$.

Diez años después, a fines de 1915 y a principios de 1916, Caso impartió un curso que llegó a ser muy famoso, y que ofrecía "una síntesis del cristianismo colegida de la biografía moral de algunos grandes cristianos", y una visión sobre el desarrollo de las ideas y los sentimientos evangélicos a través del tiempo. El maestro abordó a San Juan Bautista, "una recia figura heroica que tiene la soledad majestuosa del desierto"; a San Pablo, "el autor práctico del Cristianismo, como fenómeno universal y no simplemente judío"; a San Agustín, el Padre de la Iglesia, que "representa la alianza de las letras humanas y la cultura clásica con la inspiración divina, y que presiente o prepara todo: el Catolicismo, el Protestantismo y el Cartesianismo"; a Carlomagno, el "soldado inmortal de la Iglesia"; a Gregorio VII, "el Pontífice, monje que ciñe la tiara y lleva al solio de Europa las virtudes austeras del claustro y el celo incoercible del verdadero vicario de Cristo"; a San Francisco de Asís, "el Místico, el héroe del sentimiento y la acción caritativa fácil, el símbolo de la felicidad cristiana expansiva, contagiosa, desbordante"; a Lutero, "quien opuso al Renacimiento la Reforma"; a Santa Teresa, "la apoteosis de la idea cristiana, la mujer cristiana, genial y sumisa a la vez, incansable fundadora y reformadora, la Santa por antonomasia"; y por último, a Pascal y Tolstoi, "los últimos grandes cristianos de la historia". La interpretación de la esencia del Cristianismo de Caso fue desarrollada después en La existencia como economía y como caridad ${ }^{56}$.

${ }^{55}$ DOMÍNGUEZ, Virgilio. (1956): "Discurso. Homenaje a don Antonio Caso en el décimo aniversario de su fallecimiento", en Revista de la Facultad de Derecho de México. México, Universidad Nacional Autónoma de México. No. 21. Enero - marzo. p. 202.

${ }^{56}$ Boletín de la Universidad Popular Mexicana. Tomo II. No. 2, junio de 1916, pp. 49 - 51. 
Tanto Gómez Morín como Cosío Villegas escribieron sus impresiones del curso de Caso. El primero recuerda que asistieron a él importantes intelectuales como Enrique González Martínez, Saturnino Herrán y Ramón López Velarde ${ }^{57}$, en tanto que el segundo afirma: "Para nosotros, los muchachos de entonces, que vivíamos en el desconcierto provocado por la barbarie que inevitablemente desató la Revolución, aquellas conferencias, a más de mantener en nosotros una noción de la existencia y del valor de la cultura, nos despertó la esperanza de que aquella barbarie pronto daría lugar a un pujante renacimiento cultural". Vale la pena recoger el testimonio asombrado de Cosío Villegas:

Durante las vacaciones del año escolar de 1915, llegábamos a la Universidad Popular de la Plaza del Carmen partiendo de la Escuela Nacional Preparatoria, y como solía faltar la luz eléctrica, nos alumbrábamos con velas de estearina, cuya débil flama protegíamos con la palma de la mano. El aspecto del salón resultaba tétrico, pues con el propósito de ahorrar velas, sólo quedaban encendidas dos, pegadas sobre la mesa a uno y otro lado del conferenciante. No veíamos, pues, sino el rostro de Caso, y eso como si estuviera labrado a hachazos, tan brutal así resultaba el contraste de la luz y la sombra, y veíamos también, sólo que fugazmente, una mano si llegaba a atravesar la reverberación de la vela. Miré y escuché a Antonio Caso mil veces más dando sus clases en condiciones enteramente normales, y por eso puedo estar seguro de que aquellas de la Universidad Popular no desmerecieron de ninguna otra. Igual calor en la exposición, idénticas muecas dramáticas, el mismo retrotraerse para anudar algún cabo de la explicación que andaba suelto por alli $i^{58}$.

Otros asistentes afirman que dichas conferencias fueron escuchadas "con salón enteramente lleno, ya que la gente ocupaba los pasillos, permaneciendo de pie todo el tiempo de la conferencia ${ }^{59}$.

Sin embargo, las reacciones ante la exuberancia discursiva de Caso eran muy variadas. Oswaldo Robles, por ejemplo, recuerda de las clases del maestro: "El auditorio apenas respiraba, el silencio hacía posible oír el deslizar rasgueante de las plumas sobre los cuadernos de notas, y cuántas veces estalló el aplauso incontenible. Los de afuera preguntaban: ¿qué hay en clase? Nosotros respondíamos orgullosos: Caso explica”. Lo confirma así Cosío Villegas: "en Caso encontramos un expositor brillantísimo, orador consumado, al mismo tiempo un gran actor" ${ }^{\prime 60}$. Krauze destaca del magisterio de Caso, "el recurso a la emoción y la recreación de imágenes"

57 GÓMEZ MORÍN, Manuel. (1973): 1915 y otros ensayos. México. Editorial Jus. p. 20.

${ }^{58}$ COSÍO VILLEGAS, Daniel. (1986): Óp., cit, p. 56.

59 "Saludo al doctor don Alfonso Pruneda", Óp., cit, p. 25.

${ }^{60}$ COSÍO VILLEGAS, Daniel. Óp., cit, p. 58. 
y liga la eficacia de la actuación del maestro con la catarsis final, el silencio precursor y la apoteosis de los aplausos ${ }^{61}$.

Los más críticos hacia el método didáctico de Caso serán Jorge Cuesta y Samuel Ramos. El primero recuerda: "No asistí sino a una o dos [clases]: salí de ellas más desalentado que antes. El entusiasmo pedagógico era algo que no había encontrado todavía en mi vida escolar. La exaltación de sus gestos y de su voz sólo consiguió atemorizarme. Yo pretendía, ingenuamente, que la filosofía era un ejercicio intelectual esforzado, pero tranquilo. Su exuberancia excedía mi poder" ${ }^{32}$.

Ramos, en tanto, anotará en forma aún más crítica: "Era Caso un consumado maestro para exponer las ideas con diáfana elocuencia, sirviéndose del gesto, la mímica y la voz para matizar sus lecciones con una variada gama patética. Daba a cada sistema que iba presentando un tono característico, y con su habilidad de mimo sabía vestir el traje de todos los filósofos. Cuando llegaba a los contemporáneos se exaltaba al punto máximo. No había en verdad mucho rigor crítico en el examen de estos últimos" ${ }^{\prime 3}$.

Alejandro Estrella señala que Antonio Caso logró crear un linaje capaz de generar nuevas problemáticas a partir de la herencia filosófica del maestro: "la mayor parte de los grandes filósofos mexicanos de la primera mitad del siglo xx se han considerado en algún momento discípulos de Caso y, además, las principales redes que emergieron del proceso de disolución de la red oficial, y que estructuraron el campo filosófico mexicano en la década de 1940, tienen su origen en una ruptura con la herencia del maestro". A juicio de Estrella, la formación de este linaje se originó precisamente en la actuación de Caso frente al grupo, es decir en "unas interacciones formales e informales intensamente focalizadas en la figura del maestro, cuya jefatura espiritual y moral se convirtió en un símbolo colectivo cargado de energía emocional". Así, en la representación colectiva de los alumnos, Caso aparecía con cierto carácter solemne, casi sagrado. Los testimonios de los alumnos coinciden en señalar "un entusiasmo pedagógico que transmitía, a través de la teatralidad de su oratoria, de sus ademanes y de la vehemencia de su voz". Concha Álvarez, alumna de Caso, da cuenta de la puesta en escena que tenía lugar en las clases del maestro:

Se bizo un silencio expectante. Empezó a hablar el maestro. Ante nuestros ojos asombrados resucitó la sociedad fastuosa y refinada de Atenas [...]. Y así continuó la cátedra, hasta la muerte del filósofo

${ }^{61}$ KRAUZE, Enrique. (2008): Caudillos culturales de la Revolución Mexicana. México: Siglo XXI Editores. p. 71.

${ }^{62}$ KRAUZE, Enrique. (2008): Öp., cit, p. 154.

${ }^{63}$ RAMOS, Samuel. (1971): "Antonio Caso", en CASO, Antonio. Obras completas. Vol. I. México. UNAM. p. 162 
que describió según la célebre apología de Platón: "sentí que mis lágrimas corrían en abundancia y me cubrí la cara con el manto para llorar sobre mí mismo. Pues no era la desgracia de Sócrates la que lloraba sino la mía, el pensar en el amigo que iba a perder". Terminó la clase. Nadie se movió de su asiento. Un silencio recogido, emocionado, siguió a sus últimas palabras. Fue después, pasado un poco la emoción, que estalló el aplauso ${ }^{64}$.

\section{Caso y sus alumnos notables. La influencia o el distanciamiento}

Cuando el Ateneo de México se disgregó tras el asesinato de Madero y el inicio de la revolución contra Huerta, sólo uno de los profesores ateneístas permaneció en la ciudad de México: Antonio Caso. En torno de él se formó el grupo de la Generación de 1915, integrado por los discípulos directos de Caso y de Henríquez Ureña. Buscaban en el pensamiento -recuerda Gómez Morín-

Un refugio, una explicación o una justificación de lo que entonces acontecía. En el inolvidable curso de Estética de Altos Estudios y en las conferencias sobre el Cristianismo en la Universidad Popular, estaban González Martínez, Saturnino Herrán, Ramón López Velarde y otros más jóvenes, todos llevados allí por el mismo impulso. En esos días, Caso labraba su obra de maestro abriendo ventanas espirituales, imponiendo la supremacía del pensamiento, y con ese anticipo de visión propia del arte, a tono con las más hondas corrientes del momento ${ }^{65}$.

Antonio Luna Arroyo, integrante de una generación posterior, recuerda haber concurrido con algunos condiscipulos "por afición", durante dos años seguidos, al curso de Sociología que Caso impartía en la Facultad de Derecho; y cursó todavía dos años más en el curso de Ética y Estética en la Escuela de Filosofía y Letras. Señala: "Nosotros estudiamos el Positivismo con el maestro Antonio Caso en el curso de Historia de las Doctrinas Filosóficas ${ }^{66}$.

En algún momento de su trayectoria, Samuel Ramos dice de Caso: "Sus cátedras eran la gloria de la Universidad de México y pronto trascendió su fama de los escolares al público no universitario... Era Caso un consumado maestro para exponer las ideas con diáfana elocuencia" ${ }^{97}$.

${ }^{64}$ ESTRELLA GONZÁLEZ, Alejandro. (2010): Óp., cit, p. 330.

${ }^{65}$ GÓMEZ MORÍN, Manuel. (1973): Óp., cit, pp. 17 - 18.

${ }^{66}$ LUNA ARROYO, Antonio. (1992): "La Facultad de Derecho de la UNAM en la historia reciente", en Revista de la Facultad de Derecho de México. México. Universidad Nacional Autónoma de México. No. 185 - 186. Septiembre diciembre. p. 159.

${ }^{67}$ LEAL, Luis. (1957): "La Generación del Centenario", en UNIVERSIDAD DE NUEVO LEÓN, Páginas sobre Alfonso Reyes. Monterrey. Universidad de Nuevo León. Tomo II. p. 432. 
El distanciamiento entre Caso y Ramos se da cuando Ramos percibe en forma muy crítica la labor docente de su maestro, y cuando "reivindica una filosofía más profesionalizada y rigurosa, menos dependiente de la autoridad carismática y más de criterios impersonales y colectivos". El encuentro con la filosofía de Ortega resulta decisivo para Ramos, quien aprecia en la propuesta del filósofo madrileño una fuente de inspiración del profesionalismo que pretendía, y que no pudo heredar de Caso. De todos modos, Gaos llevaba una relación estrecha con Caso.

"La idea central del artículo [crítico de Samuel Ramos] consiste en reconocer que Caso ocupa, sin lugar a dudas, un punto de partida para la renovación de la filosofía en México, después de cuatro décadas de positivismo. Pero, al mismo tiempo... [le critica] que su magisterio en filosofía haya quedado solamente como un buen expositor y orador de los sistemas que enseñaba; asimismo, que se haya conformado con Bergson, Boutroux y James; en suma, que se haya limitado en el intuicionismo y el pragmatismo 'en un país en que hace falta la disciplina de la inteligencia"' 68

Por su parte, Lombardo Toledano recordará con afecto a Caso en 1930:

Los que cursábamos el primer año de la Preparatoria en 1910, y que por diversas circunstancias no nos dábamos aún cuenta exacta de las quejas amargas de las masas, al llegar a la cátedra del maestro Caso oimos la revelación de nuestro pasado histórico y adquirimos la noción clara de nuestro deber de hombres y la confianza en la consecución de los designios del espiritu. Este beneficio enorme -dígolo por mí-no podemos pagarlo con nada en la vida. Aprendimos a amar a los hombres filosóficamente, que es la manera de amarlos siempre, a pesar de algunos de esos hombres... ${ }^{69}$

Pero la relación entre ambos llegaría a la ruptura tres años más tarde, debido a las profundas diferencias ideológicas y políticas que surgieron entre ambos al paso del tiempo. En forma paulatina a través de la década de 1920, Lombardo se fue integrando cada vez más al materialismo dialéctico. Por ello, su postura ideológica se halló cada vez más distante de la metafísica idealista de Caso, su antiguo maestro y amigo, con quien le unieron hilos cada vez más débiles. Finalmente, cuando Lombardo fue considerado, hacia 1933, el referente intelectual del marxismo mexicano, la confrontación con Caso resultó inevitable ${ }^{70}$.

${ }^{68}$ TREJO VILLALOBOS, Raúl. (2010): "Filosofía y vida: el itinerario filosófico de José Vasconcelos". Tesis doctoral. Salamanca. Universidad de Salamanca Departamento de Filosofía, Lógica y Estética. p. 268.

${ }^{69}$ LOMBARDO TOLEDANO, Vicente. (1930): "El sentido humanista de la Revolución Mexicana”, en CASO, Antonio; REYES, Alfonso, Óp., cit, p. 176.

${ }^{70}$ ESTRELLA GONZÁLEZ, Alejandro. (2010): Óp., cit, p. 338. 
Pero todavía hay un par de testimonios que permiten conocer mejor la figura de Caso como maestro y educador. En 1944, una reforma total cambia el orden universitario. Cuando Alfonso Caso, el rector interino, culmina la reforma, llama a Leopoldo Zea y le dice: "Mi hermano Antonio me ha pedido que le ofrezca a usted la cátedra de filosofía de la historia que él dictó y a la cual ha renunciado. Si acepta entrará por la puerta grande a la Facultad a la que una maquinación le impidió entrar antes". "Déjeme hablar antes con el maestro caso, es para mí una responsabilidad que me aterra". Antonio Caso insiste ante el propio Zea: "Usted aprenderá como yo aprendí: en la cátedra". Zea acepta y se hace cargo en 1944 de la cátedra de filosofía de la historia de la Facultad de Filosofía y Letras. El Consejo Universitario le exime de la oposición. Así se define una vocación que llegará a ser importantísima en la historia de la filosofía mexicana ${ }^{71}$.

Otro de los alumnos que recuerda en forma más clara la manera en que Caso definió su vocación, es Andrés Henestrosa. Ya a edad muy avanzada, recuerda el papel que jugó Caso para definir su vocación de escritor: "El maestro Antonio Caso, en Derecho pidió un día que alguien relatara un mito. Yo lo conté. Caso me preguntó si lo había memorizado de algún autor. No señor, le contesté, lo he oído en mi tierra en lengua indígena y aquí lo he dicho en lengua española”. Cuando leyó la pieza, me dijo: 'Hágalo con todos los que se acuerden'; ese fue el origen de Los hombres que dispersó la danza, cuya primera versión fue publicada en $1929^{\prime \prime} .{ }^{72}$

\section{CONCLUSIÓN}

A partir de los testimonios y las opiniones de quienes conocieron a Antonio Caso, sobre todo de sus contemporáneos, es posible reconstruir su figura como educador. Las observaciones de los miembros del Ateneo, por ejemplo, aportan elementos que permiten contrastar sus fortalezas con sus debilidades. Por una parte, Carlos González Peña, Isidro Fabela, Alfonso Reyes, Julio Jiménez Rueda y Alfonso Reyes extreman sus elogios hacia los actos y aún hacia la personalidad de Caso, a quien describen como amigable, bueno, generoso y sensible. En el medio, Martín Luis Guzmán admite las virtudes pedagógicas del filósofo, aunque de una manera mesurada. Y en el otro extremo, José Vasconcelos y Pedro Henríquez Ureña encontrarán defectos en su actuación como docente. Si bien todos ellos reconocen el talento del filósofo como educador, como formador de las nuevas generaciones, incluso como elocuente orador, sus coetáneos

\footnotetext{
${ }^{71}$ ZEA, Leopoldo. (1988): "Autopercepción intelectual de un proceso histórico", en Anthropos. Barcelona. No. 89. p. 17.

${ }^{72}$ La Jornada. (1993): "Publica el Fondo de Cultura Económica libro de Andrés

Henestrosa". 15 de abril. p. 16
} 
críticos señalarán, por una parte, su apatía e insociabilidad, que le impedían consolidar grupos en torno a él; y por la otra, ya dentro del aula, cierta falta de elegancia, cierta tendencia a sostener sus dichos como irrebatibles, e incluso un exceso de confianza en su reconocido don de la palabra, que podía llegar a desvirtuar sus propias ideas.

Seguramente tales virtudes y defectos incidieron en sus discípulos, porque si bien en la mayoría de los testimonios se avala y aún se elogia la cátedra de Caso, en algunos otros existe un disenso respecto a su forma expositiva. En el primer grupo están, por ejemplo, los integrantes de la Generación de 1915 (Manuel Gómez Morín, Alfonso Caso, Antonio Castro Leal, Daniel Cosío Villegas, entre otros, y sobre todo Vicente Lombardo Toledano), Antonio Luna Arroyo, Concha Álvarez y Oswaldo Robles.

En tanto, Samuel Ramos y Jorge Cuesta muestran su desacuerdo respecto a la forma en que Caso desarrolla sus clases. El primero le reputa su ausencia de rigor crítico, su falta de disciplina e incluso su incapacidad para actualizar su pensamiento mediante la exposición de autores y teorías más recientes, mientras que el segundo sencillamente huye de su clase, atemorizado por la exaltación de sus gestos y de su voz, es decir por lo que llama su exuberancia.

De cualquier forma, la opinión que ha trascendido sobre Caso a través de las épocas resulta por lo general positiva. Por eso Susana Quintanilla llama al Caso de 1912 "un maestro de una competencia indiscutible", a cuyas lecciones, "tan útiles y tan galanas", los estudiantes acudían con verdadero entusiasmo ${ }^{73}$. Del mismo modo, Engracia Loyo se refiere al filósofo como "un brillante y respetable intelectual" "74. Javier Garciadiego es aún más enfático cuando afirma que en 1915, tras la publicación de sus libros, y luego de su "celebradísima serie de charlas sobre el cristianismo", Caso "se convirtió en el principal intelectual del país", pues "sus escritos y conferencias produjeron el único motivo de debate y polémica intelectual durante esos años"; finalmente lo llama "el más destacado, popular y dedicado miembro del profesorado en su conjunto, además de ser el más decidido defensor de la institución [universitaria]"75.

Sobre la postura ideológica y la propuesta educativa de Antonio Caso, podemos concluir que ambas estaban centradas en el principio básico de la libertad y en el respecto al individuo, y que ambas se oponían decididamente

${ }^{73}$ QUINTANILLA, Susana. (2009): A salto de mata. Martín Luis Guzmán en la Revolución Mexicana. México, Editorial Tusquets. p. 142.

${ }^{74}$ LOYO, Engracia. (1999): Gobiernos revolucionarios y educación popular en México, 1911 - 1928. México, El Colegio de México, 1999. p. 53.

${ }^{75}$ GARCIADIEGO, Javier. (2000): Rudos contra cientificos. La Universidad Nacional durante la Revolución Mexicana. México, El Colegio de México / UNAM. pp. 341, 384. 
a todos los dogmatismos, sin importar su signo ideológico. El filósofo proponía un sistema pedagógico basado en la persuasión, mediante el cual el alumno, más allá de sus saberes disciplinarios, pudiera acercarse al modelo ideal de un hombre de bien: generoso, desinteresado, incluso capaz de sacrificarse en pro de los demás.

Respecto a la manera en que Caso desempeñaba su profesión docente, conviene destacar algunos rasgos. En primer lugar, fue desde su juventud una persona con una profunda y verdadera vocación de educador. Además, presentaba sus clases como una especie de puesta en escena, en donde, como todo buen actor, encarnaba apasionadamente a los personajes y vestía de vitalidad a las frías palabras, acercando las teorías a la inteligencia de los alumnos por las vías del interés, el entusiasmo y aún la exaltación. Finalmente, no sólo transmitía a sus alumnos ideas, sino también emociones, y sobre todo energía. De ahí el asombro, por eso la admiración que despertaba en sus discípulos -su arrobado público-, a los que, según los testimonios, se entregaba por completo.

En su papel de filósofo, Caso escribió obras notables, en las que manifestaba una manera original de contemplar la realidad, a partir del idealismo y el pragmatismo. Incluso, a juicio de Juan Mora, presintió "la necesidad de hacer una filosofía desde las condiciones específicas de México; a partir de estas reflexiones se desarrolló el pensamiento de la nueva generación. A Caso le cupo, entonces, el mérito de darle paso a una posible filosofía latinoamericana" ${ }^{\prime 76}$. Sin embargo, si se hubiera limitado a ser filósofo, su pensamiento seguramente no hubiera trascendido como lo hizo. En cambio, desde su juventud decidió abrazar la enseñanza, en la cual se realizaba plenamente día a día, clase por clase.

Por eso, en muchos sentidos, Antonio Caso fue un iniciador, precisamente desde su labor docente, de una nueva propuesta universitaria. Al fundar el Ateneo de la Juventud, de evidente vocación pedagógica, encauzó las aspiraciones de los jóvenes escritores y artistas, dándoles un rumbo firme y combativo. Al fundar la enseñanza de la filosofía al interior de la Universidad Nacional, debilitó desde sus cimientos la fortaleza monologante del positivismo y terminó por demolerla. Y al iniciar los cursos de estética, abrió a las jóvenes generaciones de humanistas una nueva perspectiva para observar la realidad y estudiar la sensibilidad, a partir de las manifestaciones artísticas ${ }^{77}$.

${ }^{76}$ MORA RUBIO, Juan. (1980): "Proyectos y perspectivas de la Filosofía en México”, en Dialéctica. Puebla, Universidad Autónoma de Puebla - Escuela de Filosofía y Letras, Año V, Vol. 9, Diciembre. p. 63.

${ }^{77}$ Samuel Ramos escribió: "Caso es de modo absoluto el iniciador del estudio de la estética en México". CASTRO LEAL, Antonio. (1962): "La estética en México", en Memoria del Colegio Nacional 1961, México, El Colegio Nacional. T. IV, p. 93. 
En su trayectoria como educador, Caso realizó las funciones más importantes que le son encomendadas al maestro: enseñar, encauzar sentimientos, definir vocaciones. De allí que su vida tuviera, en un sentido modélico, mayor vigencia que su propia obra.

Antonio Caso decía: "la cultura no puede ser dogmáticamente definida, porque su esencia es creación, creación de valores" ${ }^{\prime 7}$. En esta definición, no dejaba de pensar en la dimensión docente de su propia existencia. Porque los valores creados por la cultura no tendrían sentido si no fueran difundidos, transmitidos, enseñados. Solo mediante la enseñanza los valores tienen una verdadera trascendencia, y Caso llegó a esta verdad no sólo de manera teórica, sino desde el ejercicio cotidiano de la docencia, que constituye una actividad esencialmente generosa.

\section{FUENTES}

CASO, Antonio. (1985): "La cultura universitaria y el materialismo histórico"

CASO, Antonio, Obras completas. México, Universidad Nacional Autónoma de México. Tomo X.

CASO, Antonio. (1916): La existencia como economía y como caridad. Ensayo sobre la esencia del cristianismo. México, Librería de Porrúa Hermanos.

CASO, Antonio. (1926): "Los cuatro poetas. Dante, Cervantes, Shakespeare, Goethe: ni uno más ni uno menos", en Revista Nuevos Ritos. Panamá. Junio - julio.

CASO, Antonio. (1976): Obras completas. México, Universidad Nacional Autónoma de México. Tomo X.

CASO, Antonio; REYES, Alfonso, et al. (2000): Conferencias del Ateneo de la Juventud. Seguido de Anejo documental. México, Universidad Nacional Autónoma de México - Coordinación de Humanidades.

El Demócrata. (1917): "Entrevista a Antonio Caso". Jueves 31 de mayo. Portada. México, D. F.

La Jornada. (1993): "Publica el Fondo de Cultura Económica libro de Andrés Henestrosa". 15 de abril. p. 16

${ }^{78}$ CASO, Antonio. (1985): "La cultura universitaria y el materialismo histórico", en CASO, Antonio, Obras completas. México, Universidad Nacional Autónoma de México. Tomo X, p. 154. 


\section{REFERENCIAS}

CASTRO LEAL, Antonio. (1962): "La estética en México", en Memoria del Colegio Nacional 1961, México, El Colegio Nacional. T. IV.

CASTRO, Eusebio. (1954): "Trayectoria ideológica de la educación en México", en Historia Mexicana. México, El Colegio de México - Centro de Estudios Históricos. Vol. 4. No. 2 (14). Octubre - diciembre.

COSÍO VILLEGAS, Daniel. (1986): Memorias. México, Joaquín Mortiz / SEP (Lecturas Mexicanas, Segunda Serie, 55).

CONTRERAS PÉREZ, Gabriela. (2004): "La universidad: nacional y autónoma", en Perfiles Educativos. México, Universidad Nacional Autónoma de México. Tercera época. Año / Vol. XXVI. No. 105 - 106.

CURIEL, Fernando. (1999): La revuelta. Interpretación del Ateneo de la Juventud. México, Universidad Nacional Autónoma de México - Instituto de Investigaciones Filológicas.

CUEVA PERUS, Marcos. (2009): "Antonio Caso, el personalismo y nuestra América", en Latinoamérica. Revista de Estudios Latinoamericanos. México. Universidad Nacional Autónoma de México. No. 48. enero - junio.

CHÁvEZ GONZÁLEZ, Mónica. (2004): “Antonio Caso y los paradigmas de la nación mexicana", en: Cuicuilco. México. Escuela Nacional de Antropología e Historia. Nueva Época, Vol. 11, No. 30.

DE LA MORA, Rogelio. (2009): "En torno a las élites culturales y políticas en América Latina de inicios del siglo XX", en: Sociedad y discurso. Revista electrónica de Español y Estudios Internacionales del Departamento de Lenguas, Cultura y Estética. Aalborg, Universidad de Aalborg. No. 15.

FABELA, Isidro. (1959): "Antonio Caso. El hombre", en: Antología del pensamiento universal, de Isidro Fabela. Editorial Costa - Amic. Tomo I.

GARCIADIEGO DANTAN, Javier. (1996): "De Justo Sierra a Vasconcelos. La Universidad Nacional durante la Revolución Mexicana", en: Historia Mexicana. Vol. XLVI. No. 4.

GARCIADIEGO, Javier. (2000): Rudos contra cientificos. La Universidad Nacional durante la Revolución Mexicana. México, El Colegio de México / UNAM.

GARCIADIEGO, Javier. (2006): "La oposición conservadora y de las clases medias al cardenismo", en: Istor. Año VI. No. 25. Verano.

GÓMEZ MORÍN, Manuel. (1973): 1915 y otros ensayos. México, Editorial Jus.

GONZÁLEZ PEÑA, Carlos. (1946): Gente mía. México, Editorial Stylo.

GÓMEZ QUIÑONES, Juan. (2007): "Antonio Caso, las ironías de un modernista subversivo", en: Relaciones. Estudios de Historia y Sociedad. Zamora, El Colegio de Michoacán. Vol. XXVIII. No. 109. Invierno.

HERNÁNDEZ LUNA, Juan. (1954): Imágenes históricas de Hidalgo. México, Universidad Nacional Autónoma de México - Consejo de Humanidades.

HERNÁNDEZ LUNA, Juan. (1967): “Sobre la fundación de la Universidad Nacional. Antonio Caso vs Agustín Aragón”, en: Historia Mexicana. México, El Colegio de México. Vol. XVI. No. 3. 
HERNÁNDEZ LUNA, Juan. (1969): "Polémica de Caso contra Lombardo sobre la Universidad", en Historia Mexicana. El Colegio de México - Centro de Estudios Históricos. Vol. 19. No. 1 (73). julio-septiembre.

HERNÁNDEZ LUNA, Juan. (1970): "Una polémica en torno al neokantismo", en: Historia Mexicana. México, El Colegio de México. Vol. XIX. No. 3.

HERNÁNDEZ PRADO, José. (2002): “Intuicionismo y ‘sentido-comunismo' en Antonio Caso", en DURÁN AMAVIZCA, Norma (Comp.), Acta philosofica. México, Universidad Nacional Autónoma de México - Facultad de Filosofía y Letras, Dirección General de Asuntos del Personal Académico.

HERNÁNDEZ PRADO, José. (2000): "El liberalismo de Antonio Caso”, en: Sociológica. Universidad Autónoma Metropolitana - Azcapotzalco. Año 15. No. 43. Mayo - agosto.

KRAUZE, Enrique. (2008): Caudillos culturales de la Revolución Mexicana. México, Siglo XXI Editores.

LEAL, Luis. (1957): "La Generación del Centenario", en: Universidad de Nuevo León, Páginas sobre Alfonso Reyes. Monterrey. Universidad de Nuevo León. Tomo II.

LOYO, Engracia. (1999): Gobiernos revolucionarios y educación popular en México, 1911 - 1928. México, El Colegio de México.

MAGALLÓN ANAYA, Mario. (2007): "Samuel Ramos y su idea de cultura en México", en: Temas de Ciencia y Tecnología. Oaxaca, Universidad Tecnológica de la Mixteca. Vol. 11. No. 33. Septiembre - diciembre.

MANTILLA MOLINA, Roberto L. (1957): "Discurso", en: Revista de la Facultad de Derecho de México. México, Universidad Nacional Autónoma de México. No. 28. Octubre - diciembre.

MONTES DE OCA, Elvia. (2008): "La disputa por la educación socialista en México durante el gobierno cardenista", en: EDUCERE. La revista venezolana de educación. Mérida, Venezuela, Universidad de Los Andes. Año 12. No. 42. Julio, agosto, septiembre.

MORA RUBIO, Juan. (1980): "Proyectos y perspectivas de la Filosofía en México", en: Dialéctica. Puebla, Universidad Autónoma de Puebla - Escuela de Filosofía y Letras, Año V, Vol. 09, Diciembre.

OCAMPO LÓPEZ, Javier. (2005): "José Vasconcelos y la educación mexicana”, en: Revista Historia de la Educación Latinoamericana. Tunja, Universidad Pedagógica y Tecnológica de Colombia. No. 7.

OLIVARES VARGAS, Rigel. (2005): "El concepto de intuición en Antonio Caso", en: Iztapalapa. Revista de Ciencias Sociales y Humanidades. México, Universidad Autónoma Metropolitana - Iztapalapa. No. 58.

PALAZÓN MAYORAL, María Rosa. (2010): "Reflexiones sobre el significado y límites del término estética", en: Eikasia. Revista de Filosofía. Oviedo. Año 5. No. 33. julio.

QUINTANILLA, Susana. (2009): A salto de mata. Martín Luis Guzmán en la Revolución Mexicana. México, Editorial Tusquets.

RAMOS, Samuel. (1971): “Antonio Caso", en: CASO, Antonio. (1976): Obras completas. México, Universidad Nacional Autónoma de México. Tomo I. 
ROBLES, Martha. (1985): Educación y sociedad en la historia de México. México, Siglo XXI Editores.

SALINAS QUIROGA, Genaro. (1980): Los siete sabios de México. México, Universidad de Nuevo León.

SÁNCHEZ CUERVO, Antolín. (2009): "El exilio del 39 y su contribución a la reflexión sobre la filosofía en lengua española", en: Revista de Hispanismo Filosófico. Madrid. Asociación de Hispanismo Filosófico. No. 14.

SANGINÉS GARCÍA, Esther. (2009): "La transmutación por el espíritu. Ensayo sobre la economía, el amor y el sacrificio en Antonio Caso y José Vasconcelos", en: Devenires. Revista de filosofía y filosofía de la cultura. Morelia. Universidad Michoacana de San Nicolás de Hidalgo. Año X. No. 19. Enero de 2009.

SILVA MARTÍNEZ, Guillermo Jorge. (2006): “Antonio Caso (1883-1946)", en: MAgALlÓN ANAYA, Mario. (Coord.). Personajes latinoamericanos del siglo $X X$. México, Universidad Nacional Autónoma de México - Centro Coordinador y Difusor de Estudios Latinoamericanos.

TORRES AGUILAR, Morelos (2010): Cultura y revolución. La Universidad Popular Mexicana (ciudad de México, 1912-1920). México, Universidad Nacional Autónoma de México - Coordinación de Humanidades.

TORRES BODET, Jaime. (1948): “Homenaje al maestro Antonio Caso", en: Educación y concordia internacional. Discursos y mensajes (1944 - 1947). México, El Colegio de México.

UNIVERSIDAD DE NUEVO LEÓN. (1957): Páginas sobre Alfonso Reyes. Edición de homenaje. Monterrey, Universidad de Nuevo León. 2 tomos.

URANGA, Emilio. (1969): “José Gaos: personalidad y confesión”, en: Cuadernos Americanos. México. Año XXVIII. Vol. CLXVI. No. 5. septiembre-octubre.

VASCONCELOS, José. (1935): Ulises Criollo. México, Ediciones Botas.

VAN HECKE, An. (1988): "El Ateneo de la Juventud: ética y estética de una generación", en: Espéculo. Revista de Estudios Literarios. Madrid, Facultad de Ciencias de la Información de la Universidad Complutense. No. 44. Año XIV. marzo-junio 2010. [http://www.ucm.es/info/especulo/numero44/ ateneojo.html]

ZAÏTZEFF, Serge I. (1989): "Alfonso Reyes y Antonio Castro Leal: un diálogo literario", en: Actas del IX Congreso de la Asociación Internacional de Hispanistas. Berlín / Frankfurt.

ZEA, Leopoldo. (1988): "Autopercepción inteletual de un proceso histórico", en: Anthropos. Barcelona. No. 89.

TORRES AGUILAR, Morelos. (2011): "Antonio Caso, educador universitario" en: Revista Historia de la Educación Latinoamericana Vol. 13 No. 17, Tunja, Universidad Pedagógica y Tecnológica de Colombia, RUDECOLOMBIA, SHELA- HISULA. pp. 285-314 